\title{
Fetal maturity and morbidity as related to placental weight and secondary ossification
}

\author{
J. Pryse-Davies \\ M.D., F.R.C.Path.
}

\begin{abstract}
Bernhard Baron Memorial Research Laboratories of Queen Charlotte's Maternity Hospital and Institute of Obstetrics and Gynaecology of the University of London
\end{abstract}

\section{Summary}

The problem of objectivity in histopathology is illustrated by an attempt to determine the normal range and significance of two observations, placental weight and secondary ossification, made in perinatal pathology. Neither offered a satisfactory estimation of fetal maturity. The placental weight provided little evidence of any primary placental dysfunction: the placenta was very small in association with only $\mathbf{5 0} \%$ of the very small infants and a very small placental fetal weight ratio was an infrequent finding of doubtful significance. A method of classifying relatively retarded and advanced secondary ossification was devised. Significant retardation was found in association with males, growth retardation, some malformations, and multiple births: significantly advanced ossification was found in anencephaly.

IN any scientific discipline, progress must depend upon the collection of data, imagination in the detection of patterns of association, and objectivity in testing their credibility. This paper illustrates the problem of objectivity in this sense and describes an attempt to evaluate the usefulness of measuring placental weight and secondary ossification centres as indices of fetal maturity and morbidity. Fuller details of these studies may be found in references given below.

\section{Materials and methods \\ Placenta}

A normal range of trimmed placental weights was determined for a hospital population from a consecutive series of 202 uncomplicated deliveries near term (Pryse-Davies, Beazley and Leach, 1973).

An estimate of the range of placental weights for the last trimester of pregnancy was obtained from perinatal necropsies: 402 placentae were available for assessment and 108 least likely to be affected by growth abnormalities or pathological lesions were selected by excluding cases with infarction, haemorrhage maceration, congenital malformations, multiple births, hydrops fetalis and very small infants below the 2 s.d. in birth weight for their gestation (Usher and McLean, 1969).

\section{Secondary ossification}

Ossification centre development was assessed bilaterally in the fetal limbs by whole body postmortem radiographs and the maximum diameters of each centre measured. Three hundred and seventynine necropsy radiographs were available for study. A range of number and diameter was estimated from 164 selected cases (Pryse-Davies, Smitham and Napier, 1974).

\section{Results \\ Placenta}

The trimmed placental weight and the ratio of placental weight to fetal birth weight (P : F ratio) showed a normal distribution in the 202 uncomplis cated deliveries at 38 to 43 weeks' gestation. The mean placental weight and standard deviation (s.d.) was $489 \pm 97 \mathrm{~g}$ with a 2 s.d. range of $295-683 \mathrm{~g}$. The mean $\mathrm{P}: \mathrm{F}$ ratio and s.d. was $14.6 \pm 2.3 \%$ with a 2 s.d. range of $10 \cdot 0-19 \cdot 3 \%$.

Table 1 shows the relationship between placental weight, P : F ratio and gestation estimated from the 108 selected necropsies. The correlations between placental weight and between $P$ : F ratio and gestation are highly significant statistically. Using Table 1 very small placental weights and $P$ : $F$ ratios were defined as values below the 2 s.d. range for gestation. Table 2 shows the incidence of such very small placentae, birth weights and $P: F$ ratios in the necropsy series.

\section{Secondary ossification}

During the last trimester of pregnancy secondary ossification begins in the os calcis (1) and progressively involves the talus (2), distal femur (3), proximal tibia (4), cuboid (5) and proximal humerus (6). Table 3 relates these six stages of ossification, the total diameters of the secondary centres and the bilateral os calcis diameters to gestation. The correlation between the stages and between the centre diameters and gestation is highly significant statistically. The expected normal stages were determined by taking the stage (or stages) including not less than $60 \%$ of cases around the central value for each gestational age. 
TABLE 1. Trimmed placental weights and placental-fetal $(P: F)$ weight ratios according to gestation in 108 selected fresh necropsies

\begin{tabular}{cccc}
\hline $\begin{array}{c}\text { Gestation } \\
\text { (weeks) }\end{array}$ & $\begin{array}{c}\text { No. of } \\
\text { cases }\end{array}$ & $\begin{array}{c}\text { Mean placental weight } \pm \\
\text { s.d. with 2 s.d. range (g) }\end{array}$ & $\begin{array}{c}\text { Mean P : F weight ratio } \pm \\
\text { s.d. with 2 s.d. range (\%) }\end{array}$ \\
\hline $25-26$ & 14 & $204 \pm 43(118-290)$ & $23 \cdot 5 \pm 3 \cdot 4(16 \cdot 7-30 \cdot 3)$ \\
$27-28$ & 18 & $240 \pm 31(178-302)$ & $23 \cdot 5 \pm 3 \cdot 8(15 \cdot 9-31 \cdot 1)$ \\
$29-30$ & 14 & $256 \pm 38(180-332)$ & $20 \cdot 2 \pm 2 \cdot 9(14 \cdot 4-26 \cdot 0)$ \\
$31-32$ & 9 & $306 \pm 57(192-420)$ & $18 \cdot 4 \pm 2 \cdot 5(13 \cdot 4-23 \cdot 4)$ \\
$33-34$ & 7 & $345 \pm 40(265-425)$ & $17 \cdot 0 \pm 1 \cdot 7(13 \cdot 6-20 \cdot 4)$ \\
$35-36$ & 7 & $395 \pm 66(263-527)$ & $16 \cdot 5 \pm 1 \cdot 7(13 \cdot 1-19 \cdot 9)$ \\
$37-38$ & 8 & $396 \pm 79(238-554)$ & $13 \cdot 4 \pm 2 \cdot 4(8 \cdot 6-18 \cdot 2)$ \\
$39-40$ & 21 & $476 \pm 71(334-618)$ & $14 \cdot 0 \pm 2 \cdot 2(9 \cdot 6-18 \cdot 4)$ \\
$41-42$ & 10 & $484 \pm 87(310-658)$ & $13 \cdot 9 \pm 2 \cdot 9(8 \cdot 1-19 \cdot 7)$ \\
\hline
\end{tabular}

TABLE 2. The incidence $(\%)$ of very small* birth weights, placentae and placental : fetal weight ratios in 276 fresh necropsies

\begin{tabular}{lr}
\hline Very small birth weight & 22 \\
Very small placenta & 13 \\
Very small birth weight with very small placenta & 9 \\
Very small placenta without very small birth weight & 4 \\
Very small placenta : birth weight ratio & 3 \\
\hline
\end{tabular}

* Very small = less than the appropriate 2 s.d. limit.

TABLE 3. The number of secondary ossification centres, total centre diameters and both os calcis diameters according to gestation in 164 selected fresh necropsies

\begin{tabular}{cccccc}
\hline $\begin{array}{c}\text { Gestation } \\
\text { (weeks) }\end{array}$ & $\begin{array}{c}\text { No. of } \\
\text { cases }\end{array}$ & $\begin{array}{c}\text { Expected normal no. } \\
\text { of centres (actual } \\
\text { range) }\end{array}$ & $\begin{array}{c}\text { Mean total diameter } \\
\pm \text { s.d. and } 2 \text { s.d. } \\
\text { range (mm) }\end{array}$ & $\begin{array}{c}\text { Mean os calcis } \\
\text { diameter } \pm \text { s.d. } \\
\text { and 2 s.d. range (mm) }\end{array}$ \\
\hline $21-22$ & 5 & 0 & $(0-1)$ & 0 & \\
$23-24$ & 10 & 1 & $(0-2)$ & $3 \pm 3(0-9)$ & 0 \\
$25-26$ & 19 & 1 & $(0-2)$ & $6 \pm 4(0-14)$ & $3 \pm 3(0-9)$ \\
$27-28$ & 15 & 2 & $(1-2)$ & $13 \pm 6(1-25)$ & $9 \pm 3(0-12)$ \\
$29-30$ & 23 & 2 & $(1-3)$ & $16 \pm 7(2-30)$ & $12 \pm 3(6-18)$ \\
$31-32$ & 13 & 2 & $(2-3)$ & $22 \pm 6(10-34)$ & $15 \pm 3(9-21)$ \\
$33-34$ & 13 & 2 & $(2-4)$ & $30 \pm 11(8-52)$ & $17 \pm 3(11-23)$ \\
$35-36$ & 18 & 2 or $3(1-4)$ & $35 \pm 10(15-55)$ & $20 \pm 3(14-26)$ \\
$37-38$ & 12 & 3 or $4(3-6)$ & $50 \pm 12(26-74)$ & $22 \pm 3(16-28)$ \\
$39-40$ & 22 & 3 or $4(2-6)$ & $57 \pm 12(33-81)$ & $24 \pm 3(18-30)$ \\
$41-42$ & 14 & 5 or $6(3-6)$ & $70 \pm 16(38-102)$ & $26 \pm 3(20-32)$ \\
\hline
\end{tabular}

TABLE 4. Summary of trends of secondary ossification centre development in 379 perinatal necropsies

\begin{tabular}{lc}
\hline \multicolumn{1}{c}{ Groups compared (No. of cases) } & $P$ \\
\hline $\begin{array}{l}\text { Male (214) fewer than female (165) } \\
\text { Small-for-dates below 10th centile (124) } \\
\text { fewer than normal-for-dates (198) }\end{array}$ & $<0.001$ \\
$\begin{array}{l}\text { Malformations (57) fewer than no } \\
\text { malformations (322) }\end{array}$ & $<0.001$ \\
$\begin{array}{l}\text { Multiple births (24) fewer than singletons } \\
\text { (355) }\end{array}$ & $<0.05$ \\
$\begin{array}{l}\text { Toxaemia of pregnancy (31) fewer than no } \\
\text { toxaemia (348) }\end{array}$ & $>0.05$ \\
$\begin{array}{l}\text { Multiparae (257) fewer than primiparae } \\
\text { (122) }\end{array}$ & $>0.05$ \\
$\begin{array}{l}\text { Maternal age 35-46 (59) fewer than 25-34 } \\
\text { (197) fewer than 16-24 (123) }\end{array}$ & $>0.05$ \\
$\begin{array}{l}\text { Indian (18) fewer than Caucasian (324) } \\
\text { fewer than Negro (32) }\end{array}$ & $\begin{array}{c}\text { Too few } \\
\text { non-Caucasian } \\
\text { cases }\end{array}$ \\
\hline
\end{tabular}

All 379 perinatal cases were classified as normal, advanced or retarded in ossification according to the $\delta$ normal range shown in Table 3. This enabled comparisons to be made between various groups of cases indicated in Table 4. Thus, although ossification centre development is related to gestational age, 을. there are significant differences according to sex, growth retardation, congenital malformations and multiple pregnancy. Ossification was relatively $\mathcal{O}^{\circ}$ retarded in association with pre-eclamptic toxaemia, increasing parity and maternal age but not at ao statistically significant level. There were too few cases for statistical analysis of racial association but ${ }_{\Phi}^{\complement}$ Negroes were more advanced than Caucasians and $\stackrel{\oplus}{+}$ Indians.

Several factors affect each case and this can be $\stackrel{0}{\circ}$ seen by subdividing the small-for-dates infants in 
TABLE 5. Secondary ossification and small-for-dates infants (less than 10th centile) at necropsy

\begin{tabular}{lcc}
\hline Subgroup (No. of cases) & $\begin{array}{c}\text { Advanced } \\
\text { ossification } \\
(\%)\end{array}$ & $\begin{array}{c}\text { Retarded } \\
\text { ossification } \\
(\%)\end{array}$ \\
\hline Male (72) & 8 & 36 \\
Female (67) & 18 & 27 \\
Multiple births (12) & 17 & 33 \\
Malformations (43) & 26 & 30 \\
'Primary' (87) & 8 & 32 \\
All small-for-dates infants (139) & 11 & 32 \\
Selected normal (164) & 14 & 16 \\
\hline
\end{tabular}

TABLE 6. Secondary ossification and lethal malformations

\begin{tabular}{lcc}
\hline $\begin{array}{c}\text { Type of malformation } \\
\text { (No. of cases) }\end{array}$ & $\begin{array}{c}\text { Advanced } \\
\text { ossification } \\
(\%)\end{array}$ & $\begin{array}{c}\text { Retarded } \\
\text { ossification } \\
(\%)\end{array}$ \\
\hline Anencephaly (20) & 40 & 5 \\
Other CNS (11) & 9 & 36 \\
Heart (7) & 28 & 29 \\
Renal (6) & 0 & 33 \\
Trisomy D and E (6) & 17 & 66 \\
Chondrodystrophy (2) & 0 & 100 \\
Others: multiple (5) & 40 & 40 \\
All malformed cases (57) & 24 & 30 \\
Selected normal (164) & 14 & 16 \\
\hline
\end{tabular}

Table 5. Compared with the selected normal cases, some subgroups show a relative increase of both advanced and retarded ossification. Advanced ossification is most frequent in the congenital malformations and these are further subdivided in Table 6 which shows that anencephaly is especially associated with advanced, and trisomy $\mathrm{D}$ and $\mathrm{E}$ with retarded. secondary ossification.

\section{Discussion \\ Placenta}

Although the placental weight and $P: F$ ratio have a highly significant correlation with gestation, the 2 s.d. ranges of these measurements are too wide for their use in estimating maturity: some values would be appropriate for a range for 12 weeks' gestation or more.

It has been claimed that a relatively small placenta is an index of poor placental function. This may be so in that about half the very small infants were found to have very small placentae in the fresh perinatal necropsy series (Table 2). However, growth retardation may be more easily and simply assessed by weighing the infant rather than the placenta. Only $4 \%$ of cases were found to have a very small placenta without a very small birth weight: this is supported by an incidence of only $3 \%$ of cases with a very small $\mathrm{P}: \mathrm{F}$ ratio. If a 2 s.d. range with $95 \%$ confidence limits is used to determine 'normal' $2.5 \%$ of a normal distribution might still be expected to occur above and below these limits. An incidence of $4 \%$ and $3 \%$ below the 2 s.d. limit is little more than the expected $2.5 \%$ and this indicates that selective reduction in placental weight compared with birth weight is not at all common in perinatal pathology. This may in part be due to the variable blood content of the placenta interfering with the sensitivity of this measurement but it also suggests that selective placental dysfunction is not a significant problem. It is important to remember that the placental disc only comprises part of the functional unit of maternofetal exchange and that the placental bed and uterine vasculature are absent.

\section{Secondary ossification}

The number and size of secondary ossification centres are also of limited value in estimating maturity in the individual case although the 2 s.d. range of diameters for gestational age is not so wide as that of placental weight: certain values would still be appropriate over a 12-week range.

When perinatal autopsies were analysed by comparing various subgroups of cases significant differences, such as variations with sex and type of congenital malformation, were found which were not appreciable in the study of placental weight. There are difficulties, however, in allowing for multifactorial effects in the individual case.

Factors controlling ossification are poorly understood but are probably genetic, nutritional and endocrine (pituitary, thyroid, adrenals and gonads) acting via the mother, placenta and fetus. The causes of individual variations are complex. The increased rate of ossification in anencephaly may be due to an abnormal hypothalamus with reduced production of anterior pituitary growth hormone and increased thyroid activity.

It must be appreciated, however, that the methods of estimating the normal number of ossification centres and the normal placental weights with $\mathbf{P}: \mathbf{F}$ ratios are not strictly comparable. The normal range in the former is $60-80 \%$ of selected cases while in the latter it is $95 \%$ ( 2 s.d. limits).

It must also be remembered that in both these studies the estimate of gestational age depends on an accurate maternal menstrual history. If ovulation occurs between day 8 and day 19 of the menstrual cycle and gestation is calculated to the nearest completed week, an error of 2-3 weeks at least is possible in the calculated gestational age of every case.

\section{References}

Pryse-Davies, J., Beazley, J.M. \& Leach, G. (1973) A study of placental size and chorio-amnionitis in a consecutive series of hospital deliveries. The Journal of Obstetrics and Gynaecology of the British Commonwealth, 80, 246. 
Pryse-Davies, J., Smitham, J.H. \& Napier, K. (1974) Factors influencing development of secondary ossification centres in the fetus and newborn. A postmortem radiological study. Archives of Disease in Childhood, 49, 425.
USHER, R. \& MCLEAN, F. (1969) Intra-uterine growth liveborn Caucasian infants at sea-level: standards obtained from measurements in 7 dimensions of infants born. between 25 and 44 weeks of gestation. Journal of Pediatric 74, 901. 